\title{
Reduction in left ventricular wall thickness after deconditioning in highly trained Olympic athletes
}

\author{
Barry J Maron, Antonio Pelliccia, Antonio Spataro, Maristella Granata
}

\begin{abstract}
Background-Clinical distinction between athlete's heart and hypertrophic cardiomyopathy in a trained athlete is often difficult. In an effort to identify variables that may aid in this differential diagnosis, the effects of deconditioning on left ventricular wall thickness were assessed in six highly trained elite athletes who had competed in rowing or canoeing at the 1988 Seoul Olympic Games. Each of these athletes showed substantial ventricular septal thickening associated with training (13-15 $\mathrm{mm}$ ) which resembled that of hypertrophic cardiomyopathy.
\end{abstract}

Methods-The athletes voluntarily reduced their training substantially for $6-$ 34 weeks (mean 13) after the Olympic competition. Echocardiography was performed at peak training and also after deconditioning, and cardiac dimensions were assessed blindly.

Results-Maximum ventricular septal thickness was $13.8(0.9) \mathrm{mm}$ in the trained state and $10.5(0.5)$ in the deconditioned state $(p<0.005)$ (change 15-33\%).

Conclusions-The finding that deconditioning may be associated with a considerable reduction in ventricular septal thickness in elite athletes over short periods strongly suggests that these athletes had a physiological form of left ventricular hypertrophy induced by training. Such a reduction in wall thickness with deconditioning may help to distinguish between the physiological hypertrophy of athlete's heart and primary pathological hypertrophy (for example, hypertrophic cardiomyopathy) in selected athletes with increased left ventricular wall thickness.

Institute of Sports

Science, Department

of Medicine Italian

National Olympic

Committee, Rome,

Italy

A Pelliccia

A Spataro

M Granata

Cardiology Branch, National Heart, Lung, and Blood Institute,

National Institutes of

Health, Bethesda,

Maryland, USA

B J Maron

Correspondence to:

Dr Barry J Maron, National Institutes of Health Building 10, Room 7B-15, Bethesda, MD20892, USA

Accepted for publication 20 July 1992
(Br Heart J 1993;69:125-128)

Long-term athletic training increases the diastolic dimension of the left ventricular cavity, the thickness of the wall, and the calculated left ventricular mass-a constellation of findings commonly known as "athlete's heart". ${ }^{1-3}$ The increase in left ventricular wall thickness is usually small, but may be more substantial in some athletes. ${ }^{2}$ Withdrawal of conditioned athletes from systematic training for even short periods has been reported to reduce left ventricular cavity dimension and mass. ${ }^{14-6}$ It has been suggested that this clinical phenomenon could be used to aid the differential diagnosis between athlete's heart (with considerable physiological left ventricular wall thickening) and primary forms of pathological hypertrophy, such as hypertrophic cardiomyopathy. ${ }^{17}$

However, previous reports of changes in left ventricular mass after the end of training have been confined largely to non-elite athletes with normal or only slightly increased ventricular septal or posterior wall thickness. ${ }^{146}$ Therefore, the extent to which deconditioning can produce an absolute reduction in left ventricular wall thickness remains uncertain. In the present study, we assessed with echocardiography the cardiac effects of deconditioning in a unique group of elite world-class athletes with left ventricular wall thickening who substantially reduced their training regimen after the 1988 Seoul Olympic Games.

\section{Patients and methods}

SELECTION OF ATHLETES

Between 1986 and 1988, 947 elite athletes were evaluated at the Institute of Sports Science (Rome, Italy); 16 showed considerable physiological left ventricular wall thickening $(\geq 13 \mathrm{~mm}$ ). Six of these 16 were selected for the present study because each had qualified for or participated in the 1988 Seoul Olympic Games and had undergone a substantial period of deconditioning immediately after that competition. All those selected were men (aged 1929 years, mean 24 ).

Five athletes were rowers (double or quadruple sculls) and one was a canoeist. At the Olympic Games three of the rowers won gold medals and the canoeist was a finalist in seventh place. None of these athletes had consistent increases in blood pressure or evidence of hyperthyroidism or use of anabolic steroids.

\section{ECHOCARDIOGRAPHY}

Cross sectional echocardiographic studies were performed with the athlete in a supine position with a commercially available Hewlett-Packard instrument (77020AC) and $3.5 \mathrm{MHz}$ transducer. Images of the heart were obtained in multiple cross sectional planes and the extent and distribution of left ventricular hypertrophy were assessed as described elsewhere. ${ }^{28} \mathrm{M}$ mode echocardiograms were derived from cross sectional images under direct anatomical visualisation and recorded at $100 \mathrm{~mm}$ per second.

In the parasternal short axis plane the left ventricle was divided into four segments: the anterior and posterior ventricular septum and the anterolateral and posterior free wall in both the proximal and distal portions of the ventricle. The diastolic left ventricular wall thickness in these regions was measured directly from the television monitor with the aid of calipers and a 


\begin{tabular}{|c|c|c|c|c|c|c|c|c|c|c|c|c|c|c|c|}
\hline No & $A g e^{\star}$ & $\begin{array}{l}\text { Max LV } \\
\text { thickness } \\
\text { (mm) } \\
\text { Pk }\end{array}$ & De & $\begin{array}{l}L V E D \\
P k\end{array}$ & $\underset{D e}{(m m)}$ & $\begin{array}{l}L V m a \\
P k\end{array}$ & $\begin{array}{c}\text { sss }(g) \\
D e\end{array}$ & $\begin{array}{l}L V M c \\
\text { index } \\
\left(g / m^{2}\right) \\
P k\end{array}$ & $\begin{array}{l}\text { ass } \\
\text { De }\end{array}$ & $\begin{array}{l}P W \\
P k\end{array}$ & $\begin{array}{c}m m) \\
D e\end{array}$ & $\begin{array}{l}\% F S \\
P k\end{array}$ & $D e$ & $\begin{array}{l}B S A \\
P k\end{array}$ & $\begin{array}{l}\left.m^{2}\right) \\
D e\end{array}$ \\
\hline $\begin{array}{l}1 \\
2 \\
3 \\
4 \\
5 \\
6\end{array}$ & $\begin{array}{l}19 \\
22 \\
23 \\
26 \\
26 \\
29\end{array}$ & $\begin{array}{l}15 \\
14 \\
13 \\
15 \\
13 \\
13\end{array}$ & $\begin{array}{l}11 \\
10 \\
11 \\
10 \\
11 \\
10\end{array}$ & $\begin{array}{l}56 \\
57 \\
60 \\
56 \\
57 \\
61\end{array}$ & $\begin{array}{l}54 \\
58 \\
60 \\
54 \\
58 \\
59\end{array}$ & $\begin{array}{l}330 \\
288 \\
331 \\
330 \\
288 \\
323\end{array}$ & $\begin{array}{l}220 \\
232 \\
295 \\
206 \\
264 \\
224\end{array}$ & $\begin{array}{l}153 \\
129 \\
153 \\
162 \\
134 \\
145\end{array}$ & $\begin{array}{l}102 \\
103 \\
137 \\
101 \\
124 \\
101\end{array}$ & $\begin{array}{l}12 \\
10 \\
12 \\
12 \\
11 \\
11\end{array}$ & $\begin{array}{r}10 \\
10 \\
12 \\
10 \\
11 \\
9\end{array}$ & $\begin{array}{l}30 \\
31 \\
32 \\
34 \\
35 \\
38\end{array}$ & $\begin{array}{l}31 \\
31 \\
33 \\
35 \\
36 \\
40\end{array}$ & $\begin{array}{l}2 \cdot 15 \\
2 \cdot 23 \\
2 \cdot 16 \\
2 \cdot 03 \\
2 \cdot 14 \\
2 \cdot 23\end{array}$ & $\begin{array}{l}2 \cdot 15 \\
2 \cdot 24 \\
2 \cdot 16 \\
2 \cdot 03 \\
2 \cdot 13 \\
2 \cdot 22\end{array}$ \\
\hline $\begin{array}{l}\text { Mean } \\
\text { SD } \\
\text { p }\end{array}$ & $\begin{array}{r}24.5 \\
3.5\end{array}$ & $\begin{array}{l}13.8 \\
0.9 \\
<0.005\end{array}$ & $\begin{array}{r}10.5 \\
0.5\end{array}$ & $\begin{array}{l}57 \cdot 8 \\
2 \cdot 0 \\
\text { NS }\end{array}$ & $\begin{array}{r}57 \cdot 1 \\
2 \cdot 3\end{array}$ & $\begin{array}{l}315 \\
19.3 \\
<0.01\end{array}$ & $\begin{array}{l}240 \\
30 \cdot 2\end{array}$ & $\begin{array}{l}146 \\
11.5 \\
<0.01\end{array}$ & $\begin{array}{l}111 \\
14 \cdot 1\end{array}$ & $\begin{array}{r}11.3 \\
0.7 \\
\text { NS }\end{array}$ & $\begin{array}{r}10.3 \\
0.9\end{array}$ & $\begin{array}{l}33.3 \\
2.7 \\
<0.02\end{array}$ & $\begin{array}{r}34 \cdot 3 \\
3 \cdot 1\end{array}$ & $\begin{array}{l}2 \cdot 15 \\
0 \cdot 06 \\
\text { NS }\end{array}$ & $\begin{array}{l}2.15 \\
0.06\end{array}$ \\
\hline
\end{tabular}

*At time of 1988 Olympic Games.

$\uparrow$ Retired from competition after Olympics and never resumed training.

$\ddagger$ Member of Olympic team but became ill and did not compete.

$\$$ Summation of $R$ and $S$ wave voltages in all precordial leads.

Summation of $R$ and $S$ wave voltages in all precordial leads.

BSA, body surface area; De, deconditioned; \%FS, percent fractional shortening of left ventricle; HR, heart rate; LV, left BSA, body surface area; De, deconditioned; \%FS, percent fractional shortening of left vent
ventricle; LVED, left ventricular end diastolic dimension; Pk, peak training; PW, posterior wall.

calibration scale produced by the instrument. The thickness of the anterior ventricular septum was assessed by an integrated analysis of the cross sectional and $\mathrm{M}$ mode recordings. We made an effort to exclude overlying trabeculations when we measured the thickness of the ventricular septal and left ventricular free wall. Left ventricular cavity dimensions were measured according to published recommendations. ${ }^{9}$ The left ventricular mass was calculated from maximum end diastolic wall thickness and cavity dimension. ${ }^{10}$

Echocardiograms were initially obtained during peak training (12 intensè training sessions per week) 8-40 weeks (mean 25) before the Olympic Games. After the Olympic competition each athlete had a complete deconditioning period of 6-34 weeks (mean 13) when they did not train in rowing. Their only physical activity was occasional recreational soccer or tennis. A second echocardiogram was subsequently recorded in five of the six athletes after a short period of light retraining involving running and low intensity conditioning in boats (six sessions per week for 6-8 weeks). In the sixth athlete, who retired from training and competition immediately after the Olympic Games, the second echocardiogram was obtained after 34 weeks of complete deconditioning.

Echocardiograms were interpreted by one observer (BJM) without knowledge of the identity of the athlete or the state of conditioning. To test interobserver variability, these measurements were compared with those made independently by another observer (AP). For the maximum left ventricular wall thickness, interobserver mean (SD) variability was 1.0 $(0.7) \mathrm{mm}$. Intraobserver variability was tested by one observer (AP) from blinded assessments a year apart: variability was $1.0(0 \cdot 4) \mathrm{mm}$.

\section{STATISTICAL ANALYSES}

Data are expressed as mean values (SD). Mean differences in variables assessed at peak training and after deconditioning were analysed by Student's paired $t$ test; a two-tailed $\mathrm{p}$ value of $<0.05$ was regarded as statistically significant.

\section{Results}

CHANGES IN LEFT VENTRICULAR WALL THICKNESS (TABLE)

During peak training maximum left ventricular wall thickness in the six athletes (the anterior ventricular septum in four and posterior septum in two was 13-15 mm (mean $13.8(0 \cdot 9)$ ). The areas of maximum wall thicknesses decreased to $10-11 \mathrm{~mm}$ after deconditioning (mean 10.5 (0.5); p < 0.005) (figs 1 and 2). Septal thickness decreased in each of the athletes by $2-5 \mathrm{~mm}$ (mean $3.3 \mathrm{~mm}$ ). The percentage change from the trained to the deconditioned states was $15-33 \%$ (mean $23 \%$ ). The thickness of the left ventricular free wall did not change significantly after deconditioning.

CHANGES IN LEFT VENTRICULAR MASS AND CAVITY DIMENSION (TABLE)

Left ventricular mass was greatly increased during peak training in each athlete $(>134$ $\left.\mathrm{g} / \mathrm{m}^{2}\right)^{10}$ and decreased significantly after detraining (315 (19) v $240(30) \mathrm{g} / \mathrm{m}^{2}(\mathrm{p}<0.01)$ change in mass $8-37 \%$ (mean $22 \%$ )). These structural changes assessed with echocardiography were also associated with a significant decrease in overall electrocardiographic voltages (table). The left ventricular end diastolic dimension was not significantly different during training and after deconditioning $(57.8$ (2) $v$ $57 \cdot 1(2) \mathrm{mm})$.

\section{OTHER FINDINGS}

The six athletes showed no significant change in blood pressure, body surface area, and resting heart rate with deconditioning (table). Also, none showed systolic anterior motion of the mitral valve or clinically relevant mitral regurgitation as assessed by colour flow imaging.

\section{Discussion}

The findings of the present study show that the deconditioning of highly trained elite athletes can induce substantial decreases in ventricular septal thickness. Our unique study group of world-class rowers and canoeists had echocardiographic evidence of athlete's heart with 


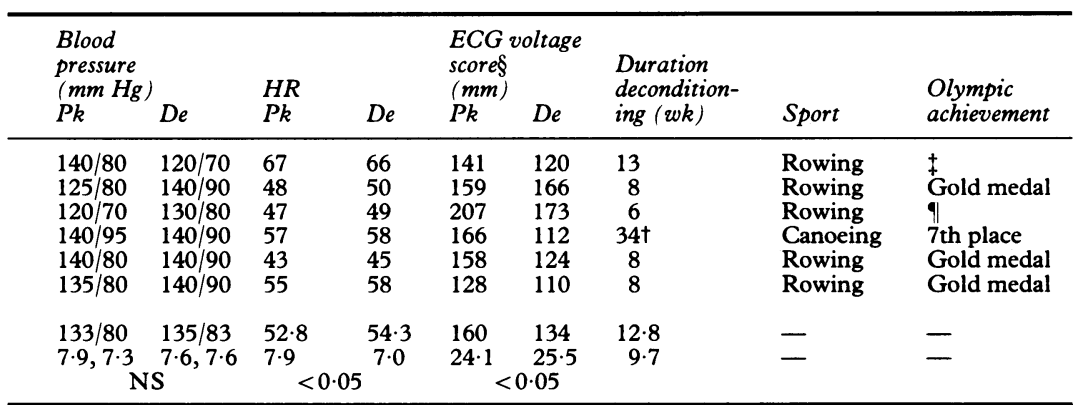

Figure 1 Changes in left ventricular wall thickness $(A)$ and mass $(B)$ associated with deconditioning in six Olympic athletes. Open symbols represent the athlete who retired from training and competition after the 1988 Olympic Games and had been deconditioned for 34 weeks at the time of the most recent echocardiographic study.
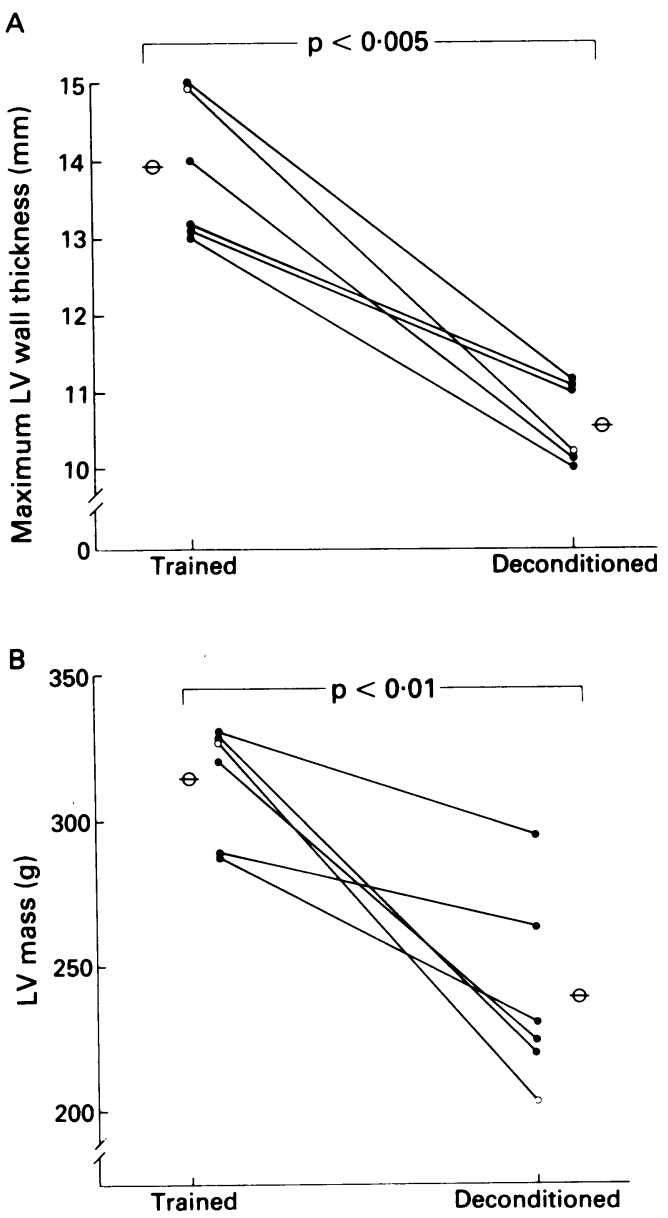

considerable septal hypertrophy. When they stopped training for 6-34 weeks after the Seoul Olympic Games blind readings of serial echocardiographic studies showed a statistically significant decrease in septal thickness (15$33 \%$ ) from those values obtained at peak training. These changes were particularly impressive because in five of the six athletes studied the lower values for wall thickness after deconditioning were obtained shortly after light training had resumed. Indeed the athlete (number 4, table) with the longest period of complete deconditioning showed the most

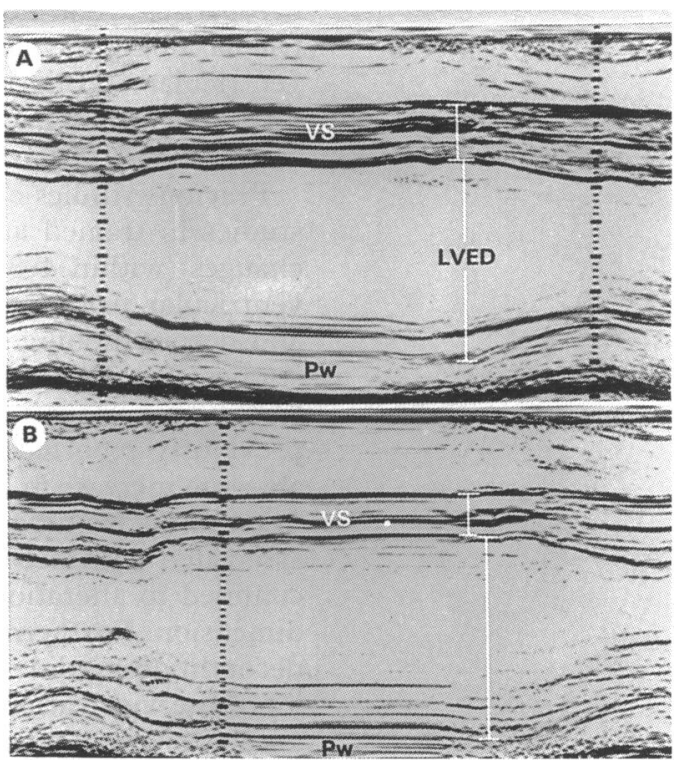

Figure 2 Serial $M$ mode echocardiograms just below mitral valve level recorded in a 26 year old Olympic rower at peak training $(A)$ and after more than eight months of complete deconditioning $(B)$. The ventricular septal (VS) thickness had decreased from 15 to $10 \mathrm{~mm}$. In addition there are also small decreases in the posterior free wall ( $p w$ ) thickness and left ventricular end diastolic cavity dimension (LVED). The large calibration marks are $1 \mathrm{~cm}$ apart.

striking decrease in wall thickness. This feature of the study design may also partly explain why left ventricular cavity size measured after deconditioning was not significantly different from peak training values. These findings resemble those reported by others who studied cardiac dimensions and maximum oxygen uptake in athletes after a reduction or short-term cessation in training. ${ }^{11} 12$

The findings of this study are relevant to the differential diagnosis of athlete's heart and hypertrophic cardiomyopathy. ${ }^{127}$ The importance of this diagnostic distinction is underlined by the fact that athlete's heart is characterised by physiologically induced left ventricular hypertrophy, ${ }^{1-6}$ while hypertrophic cardiomyopathy is probably the most common cause of sudden death in young competitive athletes. ${ }^{13}$ In highly trained athletes such as ours the thickness of the septum (13-15 mm) is similar to that in patients with mild structural expressions of hypertrophic cardiomyopathy. ${ }^{1}$ Because we found that left ventricular wall thickness was considerably reduced after deconditioning, hypertrophy in our athletes was likely to be physiological and related to training. If wall thickness had not been reduced by deconditioning a static pathological process such as hypertrophic cardiomyopathy would have been more likely. Consequently, a brief period of forced deconditioning combined with serial echocardiography may be useful in distinguishing between physiological and pathological left ventricular hypertrophy in selected athletes with absolute increases in ventricular septal thickness. We should point out that this diagnostic distinction could also be made in other ways, including identification of the familial occurrence of hypertrophic cardio- 
myopathy, ${ }^{14-16}$ a normal Doppler left ventricular filling waveform, ${ }^{17}$ or differences in left ventricular end diastolic cavity dimension or ultrasonic myocardial reflectivity (ie, backscatter signal). ${ }^{1819}$

Previous studies of serial echocardiographic studies in trained athletes also showed rapid changes (within 4-8 weeks) in calculated left ventricular mass in response to conditioning and deconditioning. ${ }^{4-6}$ However, these earlier studies differ from the present investigation in certain important respects. For example, the previously reported athletes did not show an absolute increase in left ventricular wall thickness at peak training and the observed changes associated with deconditioning were virtually confined to alterations in end diastolic cavity dimension. Furthermore, the earlier studies of deconditioning did not independently test the interobserver variability of the echocardiographic measurements, nor were assessments of cardiac dimensions before and after deconditioning always made in a rigorously blinded fashion. Therefore, the data in the present study show for the first time that increased left ventricular wall thickness associated with athletic training may be altered substantially by deconditioning.

We thank Roberto Colli and Giampietro Michelangelo for their substantial contributions.

This work was partly supported by the Italian National Olympic Committee related to work of the National Council for Research, project FATMA.

1 Maron BJ. Structural features of the athlete's heart as defined by echocardiography. J Am Coll Cardiol 1986;7:190-203.

2 Pelliccia A, Maron BJ, Spataro A, Proschan MA, Spirito P. The upper limit of physiologic cardiac hypertrophy in
highly trained elite athletes. $N$ Engl J Med 1991;324: 295-301.

3 Rost R. The athlete's heart. Eur Heart J 1982;3(suppl A): $193-8$.
4 Ehsani AA, Hagberg JM, Hickson RC. Rapid changes in left ventricular dimensions and mass in response to physical conditioning and deconditioning. Am J Cardiol 1978; 42:52-6.

5 Fagard R, Aubert A, Lysens R, Staessen J, Vanhees L, Amery A. Noninvasive assessment of seasonal variations in cardiac structure and function in cyclists. Circulation 1983;67:896-901.

6 Martin WH III, Coyle EF, Bloomfield SA, Ehsani AA Effects of physical deconditioning after intense endurance training on left ventricular dimensions and stroke volume. training on left ventricular dimension

7 Maron BJ, Bonow RO, Cannon RO, Leon MB, Epstein SE. Hypertrophic cardiomyopathy. Interrelations of clinical manifestations, pathophysiology and therapy. $N$ Engl Med 1987;316:780-9 and 844-52.

8 Maron BJ, Gottdiener JS, Epstein SE. Patterns and significance of the distribution of left ventricular hypertrophy in hypertrophic cardiomyopathy: a wide-angle, twodimensional echocardiographic study of 125 patients. $\mathrm{Am}$ J Cardiol 1981;48:418-28.

9 Sahn DJ, DeMaria A, Kisslo J, Weyman A. Recommendations regarding quantitation in M-mode echocardiography: results of a survey of echocardiographic measurements. Circulation 1978;58:1072-83.

10 Devereux RB. Detection of left ventricular hypertrophy by M-mode echocardiography: anatomic validation, standardization, and comparison to other methods. standardization, and comparison to
Hypertension 1987;9(suppl II):19-26.

11 Hickson RC, Kanakis C, Davis JR, Moore AM, Rich S. Reduced training duration effects on aerobic power, endurance, and cardiac growth. $J$ Appl Physiol Respirat Environ Exercise Physiol 1982;53:225-9.

12 Cullinane EM, Sady SP, Vadeboncoeur L, Burke M, Thompson PD. Cardiac size and $\mathrm{VO}_{2} \max$ do not decrease after short-term exercise cessation. Med Sci Sports Exerc 1986;18:420-4.

13 Maron BJ, Roberts WC, McAllister HA, Rosing DR, Epstein SE. Sudden death in young athletes. Circulation 1980;62:218-29.

14 Maron BJ, Nichols PF, Pickle LW, Wesley YE, Mulvihill JJ. Patterns of inheritance in hypertrophic cardiomyopathy. Assessment by M-mode and two-dimensional echocardiography. Am J Cardiol 1984;53:1087-94.

15 Rosenzweigh A, Watkins H, Hwang D-S, et al. Preclinical diagnosis of familial hypertrophic cardiomyopathy by diagnosis of familial hypertrophic cardiomyopathy by genetic analysis of
$1991 ; 325: 1753-60$

16 Watkins H, Rosenzweig A, Hwang D-S, et al. Characteristics and prognostic implications of myosin missense mutations in familial hypertrophic cardiomyopathy. $N$ Eng J Med 1992;326:1 108-14.

17 Lewis JA, Spirito P, Pelliccia A, Maron BJ. Utility of Doppler echocardiographic assessment of diastolic filling in distinguishing "athlete's heart" from hypertrophic cardiomyopathy. Br Heart J 1992;68:296-300.

18 Lattanzi F, Spirito P, Picano E, et al. Quantitative assessment of ultrasonic myocardial refletivity in hypertrophic cardiomyopathy. J Am Coll Cardiol 1991;17:1085-90.

19 Lattanzi F, di Bello V, Picano E, et al. Normal ultrasonic myocardial reflectivity in athletes with increased left ventricular mass. A tissue characterization study. Circulation 1992;85:1828-34. 